\title{
Management of Ludwig's angina. When is surgery necessary?
}

\author{
Oașă Irina Doinița ${ }^{1}$, Bogdan Popescu ${ }^{1,2}$, Cristian Balalau ${ }^{1,3}$, Razvan V. Scaunasu ${ }^{1,4}$, \\ Felicia Manole ${ }^{5}$, Maria Domuta ${ }^{5}$, Alina Lavinia Antoaneta Oancea ${ }^{1,2}$ \\ ${ }^{1}$ CAROL DAVILA UNIVERSITY OF MEDICINE AND PHARMACY, BUCHAREST, ROMANIA \\ ${ }^{2}$ ENT DEPARTMENT, COLTEA CLINICAL HOSPITAL, BUCHAREST, ROMANIA \\ ${ }^{3}$ GENERAL SURGERY DEPARTMENT, "SF. PANTELIMON" EMERGENCY HoSPITAL, BUCHAREST, ROMANIA \\ ${ }^{4}$ GENERAL SURGERY DEPARTMENT, COLTEA CLINICAL HOSPITAL, BUCHAREST, ROMANIA \\ ${ }^{5}$ FACULTY OF MEDICINE AND PHRAMACY, ORADEA, ROMANIA
}

\begin{abstract}
Deep neck space infections are of great risk for patients considering even death in certain cases. Collection of purulent secretions that can accumulate in a particular region of the neck is due to the anatomy of the deep neck fascia, muscles of the neck and compartments for blood vessels and organs in the neck region. Deep neck spaces communicate with each other and in some patients with morbidities like diabetes or other form of immuno-suppression extension can be great. Ludwig's angina is a form of abscess of the floor of the mouth with origin in teeth located on the mandible. Like any other abscess medical and surgical therapy are ways of treatment, but incision and drainage are mandatory. However, surgical management of such a complication might include other type of surgery as tracheostomy, blood vessels ligation, resection of necrotic tissue or even reconstruction.
\end{abstract}

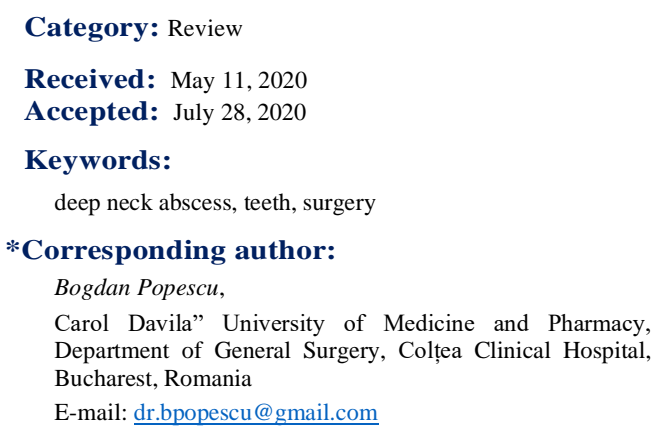

\section{Introduction}

Ludwig's angina was described in 1836 by Wilhelm Friedrich von Ludwig and ever since that time it underwent improvement in diagnosis and therapy. However, it is mandatory to correctly assess each case since the possibility of death occurs in up to $10 \%$ of cases [1,2]. The characteristic of this inflammation of the soft tissue of the tongue and floor of the tongue is that it is progressive and if not properly treated it may lead to severe morbidity. Mortality of Ludwig's angina decreased in the last decades since antibiotics had an important development. Up until this point mortality was as high as $50 \%$ [2]. The swelling of the soft tissues appear in the submandibular region as there is infectious disease spreading, in most cases, up to $90 \%$, from nearby teeth [3]. Mortality association in this case is due to several factors including upper airway obstruction, spread of abscess to other spaces of the neck and even mediastinum, as well as the evolution toward septic shock. Occurrence of the disease is typically linked with no underlying morbidity, but in some cases, it may be associated and worsened by the presence of diabetes mellitus, alcoholism, acute glomerulonephritis, aplastic anemia, neutropenia, and dermatomyositis [2,4].

Ludwig's angina poses a lot of trouble for clinicians since the diagnosis is made, mainly, under clinical examination [1,2]. Work-up for these patients needs to include blood tests and imaging studies.

\section{Discussions}

The key aspect when dealing with Ludwig's angina is diagnosis and treatment, which should be done in hospitalized environment. As we mentioned before most of the diagnosis is made by clinical examination. Crespo et al. suggested that up to $70 \%$ of deep neck space infections are underestimated and mistreated by using clinical examination alone [5]. Even if the main etiology is dental abscess spreading towards the submandibular space via mylohyoid ridge penetration as a result of molar infections, other etiologies need to be considered like trauma of the mandible with fracture, trauma of the neck region, malignant neoplasia or infection spreading from another deep space of the neck. Since there is a possibility of 
infection spread from another primary site clinicians always need to assess the possibility of infection spreading towards other spaces than the submandibular space. A contiguous spread from the submandibular space towards the parapharyngeal space, lateral or posterior might lead to severe upper airway obstruction. Spread towards the deep spaces of the neck and mediastinum can lead to increased mortality or the possibility of severe impaired function of breathing, swallowing or speech.

The main concern after Ludwig's angina diagnosis has been made is to ensure the upper airway. In the likelihood of such an event nasal or oral intubation of the patient might be needed and, in severe cases of trismus, protrusion of the base of the tongue or encirclement of the upper airway might end up in tracheostomy necessity. Needless to point out that performing a tracheostomy in patients with deep neck space abscess is related to increased morbidity on its own. Therefore, rapid assessment of the clinical status, spread of infection, associated morbidity and patency of the upper airway is of outmost importance.

Treatment guidelines have been proposed so that optimal therapy is at hand. There is no one guideline generally accepted so that recommendations rely on clinical judgement of each particular case that comes with each clinicians' experience and depending on what medical, financial and medical staff resources each medical facility can provide [6]. In this matter it is safe to say that for our clinic naso-tracheal intubation with video assistance, which is the best approach for ventilating the patient, is not at hand so that in severe airway obstruction cases most patients benefit from tracheostomy. Considering a review of the airway protection for the Ludwig's angina patients' it is safe to say that tracheostomy is the most invasive and with most associated morbidity. We need to emphasize that nazo or oro-tracheal intubation without video assistance should not be performed since it can cause the rupture of the abscess with consecutive bleeding and purulent secretions getting in the lungs [5-7]. Aspiration pneumonia is one of the most lifethreatening situations linked to Ludwig's angina.

Suppurative complications that develop from the submandibular space cellulitis require intravenous antibiotic therapy and surgical drainage. Some studies consider that up to $65 \%$ of cases require surgical management $[1,8]$. However, all the patients that were treated in our department underwent incision drainage therapy. We can consider that one of the reasons for this situation is that case selection implies that most of the complicated cases are referred to our department. All patients underwent clinical examination and endoscopic examination of the oropharynx, hypopharynx and larynx, as well as mandatory CT scan upon hospital admission.
Blood testing, allergy testing for drugs and general clinical examination completed the assessment.

Considering that the most incriminated pathogens leading to abscess formation in the submandibular space are Streptococcus species, Fusobacterium, Bacteroides spp., Staphylococcus spp., Actinomyces and gramnegative bacilli, we are using an intravenous antibiotic association regime of at least two different classes. Since this is an infection antibiotics administration must be initiated as soon as possible once we have confirmation of negative allergic reaction to recommended substances. Our most commonly used association of antibiotics is penicillin-based antibiotics, clindamycin and metronidazole, as suggested by studies that certify their efficacy [2]. If penicillin allergy is proven we can switch to an association of high doses of vancomycin and cefepime or aztreonam in association with metronidazole. Antibiotic therapy should be chosen according to the patients' status, co-morbidities (i.e. severely immunocompromised patients, severe sepsis or septic shock) or known site of infection. Initiation of therapy is empiric and is further guided by the examination of purulent secretions obtained from the abscess either by fine needle aspiration with ecographic guidance or after surgical drainage. Some case reports emphasized the benefit of early steroid use $[9,10]$.

If the status of the patient does not require airway management and drainage of the abscess at admission intravenous antibiotic and steroid administration should be continued for 48 hours and a new evaluation of the case should be performed after.

\section{Surgical management}

Two types of surgical interventions are used to treat severe Ludwig's angina cases drainage and tracheostomy. The aforementioned surgical interventions might be completed with other type of surgery since submandibular space abscess can spread to other deep neck spaces of the neck and mediastinum. Necrotic tissue debridement, either soft or bone, might be necessary to control the local and systemic evolution of the disease. Tracheostomy performed for Ludwig's angina patients has its own possible complications but is mandatory in cases in which nasal or buccal intubation are not possible. Our Ludwig's angina surgical patients underwent tracheostomy due to the severity of the airway impairment, some of them awake and under local anesthesia. It has been a more recent approach to aggressive management of the upper airway in these cases so that a more conservative care should be considered, as it was pointed out by Wolfe et al. [11]. However, when discussing therapy cost-related Potter et al. suggested that tracheotomy performed in these patients allowed an earlier discharge of the patient from the ICU, thus decreasing lower ICU and overall costs of 
hospitalization [12]. But, since the main concern is survival rates and prevention of complications, medical approach to these cases should be efficacy driven towards the wellbeing of the patients.

Drainage should be performed if there is no improvement in the local, general and biological status of the patients after 48 hours from the beginning of intravenous antibiotic and steroid therapy. For all cases that present local complications, such as osteomyelitis or tendency to spread, drainage should be performed shortly after hospital admission. Medical therapy should be initiated as soon as possible.

\section{Conclusions}

Since Ludwig's angina is a potentially life-threatening condition early diagnosis must be made. CT scans should not delay the beginning of medical therapy or in severe cases tracheostomy and drainage. If possible, video assisted intubation should be performed with consideration to the potential need for awake local anesthesia tracheostomy. Tracheostomy should be performed in cases in which video-assisted intubation is not possible or in cases in which clinicians deal with an extreme emergency of upper airway impairment. Ludwig's angina complicated with deep neck space and mediastinum spread should be treated in a more aggressive way in terms of tracheostomy and large surface drainage.

\section{Conflict of interest disclosure}

There are no known conflicts of interest in the publication of this article. The manuscript was read and approved by all authors.

\section{Compliance with ethical standards}

Any aspect of the work covered in this manuscript has been conducted with the ethical approval of all relevant bodies and that such approvals are acknowledged within the manuscript.

\section{References}

1. Moreland LW, Corey J, McKenzie R. Ludwig's angina. Report of a case and review of the literature. Arch Intern Med. 1988; 148(2): 461-466. doi: 10.1001/archinte.148.2.461

2. Bansal A, Miskoff J, Lis RJ. Otolaryngologic critical care. Crit Care Clin. 2003;19(1):55-72. doi: 10.1016/s0749-0704(02)00062-3

3. Quinn FB Jr. Ludwig angina. Arch Otolaryngol Head Neck Surg. 1999;125(5):599. doi:10.1001/archotol.125.5.599

4. Spitalnic SJ, Sucov A. Ludwig's angina: case report and review. J Emerg Med. 1995;13(4):499-503. doi: 10.1016/0736-4679(95)80007-7

5. Crespo AN, Chone CT, Fonseca AS, Montenegro MC, Pereira R, Milani JA. Clinical versus computed tomography evaluation in the diagnosis and management of deep neck infection. Sao Paulo Med J. 2004;122(6):259-263. doi:10.1590/s1516-31802004000600006

6. Marple BF. Ludwig angina: a review of current airway management. Arch Otolaryngol Head Neck Surg. 1999;125(5):596-599. doi:10.1001/archotol.125.5.596

7. Shockley WW. Ludwig angina: a review of current airway management. Arch Otolaryngol Head Neck Surg. 1999;125(5):600. doi:10.1001/archotol.125.5.600

8. Patterson HC, Kelly JH, Strome M. Ludwig's angina: an update. Laryngoscope. 1982;92(4):370-378. doi: 10.1288/00005537-198204000-00003

9. Saifeldeen K, Evans R. Ludwig's angina. Emerg Med J. 2004;21(2):242-243. doi:10.1136/emj.2003.012336

10. Freund B, Timon C. Ludwig's angina: a place for steroid therapy in its management?. Oral Health. 1992;82(5):23-25.

11. Wolfe MM, Davis JW, Parks SN. Is surgical airway necessary for airway management in deep neck infections and Ludwig angina?. J Crit Care. 2011;26(1):11-14. doi:10.1016/j.jcrc.2010.02.016

12. Potter JK, Herford AS, Ellis E 3rd. Tracheotomy versus endotracheal intubation for airway management in deep neck space infections. J Oral Maxillofac Surg. 2002;60(4):349-355. doi:10.1053/joms.2002.31218 